\title{
RELATOS DO PROJETO DE EXTENSÃO [com]VIDA NO BAIRRO DO ROSÁRIO'
}

\author{
EXTENSION PROJECT REPORTS [COM]VIDA IN BAIRRO DO ROSÁRIO
}

\author{
Marina de Alcântara ${ }^{2}$, Juliana Lamana Guma ${ }^{3}$, \\ Gabriela Petersen Coimbra ${ }^{4}$ e Luiza Weber dos Santos ${ }^{5}$
}

\begin{abstract}
RESUMO
O fazer universitário está pautado no desenvolvimento das atividades de ensino e pesquisa, que ainda assumem papel prioritário da rotina acadêmica. A extensão universitária vem ganhando espaço no fazer das universidades a partir de seu reconhecimento de potencial ferramenta para explorar as habilidades humanas e responsabilidade social na formação profissional. Este artigo, além de discutir brevemente acerca da extensão universitária, relata o primeiro ciclo de trabalho do Projeto [com]VIDA do Curso de Arquitetura e Urbanismo da Universidade Franciscana, de Santa Maria - RS. O artigo tem como objetivo apresentar as principais atividades extensionistas desenvolvidas pelo projeto junto da comunidade do Bairro Nossa Senhora do Rosário. A partir dos resultados alcançados foi possível compartilhar reflexões acerca da interação entre universidade e comunidade, constatando que as ações promovidas pelo [com]VIDA contribuíram para a qualidade ambiental de bairro e promoção da identidade local.
\end{abstract}

Palavras-chave: Extensão Universitária, Identidade, Urbanismo.

\section{ABSTRACT}

University practices are based on the development of teaching and research activities, which still assume a priority role of academic routine. The university extension has been gaining ground in the making of universities from its recognition of a potential tool to explore human skills and social responsibility in professional training. This article, in addition to discussing briefly about university extension, reports the first cycle of work of the Project [com]VIDA of the Architecture and Urbanism Course of the Universidade Franciscana, Santa Maria - RS. The article aims to present the main extension activities developed by the project to the community of the Bairro Nossa Senhora do Rosário. From the results achieved it was possible to share reflections about the interaction between university and community, noting that the actions promoted by [com]VIDA contributed to the environmental quality of neighborhood and promotion of local identity.

Keywords: University Extension, Identity, Urbanism.

\footnotetext{
1 Artigo resultado de Projeto de Extensão.

2 Arquiteta e Urbanista. Mestre em Patrimônio Cultural. Docente do Curso de Arquitetura e Urbanismo - Universidade Franciscana. E-mail: marina.alcantara@ufn.edu.br

3 Arquiteta e Urbanista, Mestre em Planejamento Urbano e Regional, docente do Curso de Arquitetura e Urbanismo Universidade Franciscana. Email: juliana.guma@ufn.edu.br

4 Acadêmica do Curso de Arquitetura e Urbanismo - Universidade Franciscana. E-mail: gabrielapetersenc@hotmail.com 5 Acadêmica do Curso de Arquitetura e Urbanismo - Universidade Franciscana. E-mail: arqluizaweber@gmail.com
} 


\section{INTRODUÇÃO: EXTENSÃO UNIVERSITÁRIA NO [com]VIDA}

A extensão é uma das três dimensões que compõem os fazeres da universidade, a saber: ensino, pesquisa e extensão. $\mathrm{O}$ ensino e a pesquisa podem ser entendidos como as funções primárias da Universidade, de modo que a extensão assume caráter diferenciado, cuja rotina de trabalho é entendida como o vínculo da academia com a comunidade. Entende-se a atividade como uma oportunidade de acadêmicos construírem sua própria visão de mundo conectados com a realidade, visando impactar positivamente o meio em que essa interação ocorre.

O papel da atividade extensionista não é unilateral, mas sim uma troca universidade-sociedade, coexistindo o saber acadêmico e o saber popular . Para Incrocci e Andrade (2018, p. 190), a extensão universitária tem "por base a interdisciplinaridade e o alcance de um público heterogêneo, posto que abarca em si a comunidade intra e a extramuros universitários".

No caso do Projeto de Extensão "Qualidade ambiental urbana: um estudo de identidade urbana para o Bairro Nossa Senhora do Rosário em Santa Maria - RS”, denominado para fins de divulgação "[com]VIDA", a aproximação da comunidade com a universidade foi feita por meio de solicitações da Associação de Moradores do Bairro Rosário (AMBRO) ao Curso de Arquitetura e Urbanismo da Universidade Franciscana. Buscando a qualificação da área, o bairro Nossa Senhora do Rosário tornou-se objeto de estudo dos acadêmicos dos cursos de Arquitetura e Urbanismo e Design.

O [com]VIDA iniciou suas atividades em agosto de 2018, buscando o reconhecimento do Bairro do Rosário a partir de referências históricas, dados oficiais e na permanência no território a partir de estudos de aproximação com a comunidade. Os objetivos iniciais, assim, concentravam-se no fortalecimento da identidade local, qualificando a apropriação dos moradores com a área de estudos e na promoção de ações que dinamizassem a vida urbana local.

Ao pensar extensão no âmbito da universidade, o [com]VIDA estruturou-se defendendo que as práticas das experiências extensionistas qualificam a formação humana e profissional dos acadêmicos, de modo que "o vivenciar da extensão em sua formação cumpre, sobremaneira, a necessária vinculação entre o conhecer e o viver" (FOREXT, 2017). Acredita-se, assim, na prática da extensão universitária baseada na responsabilidade social com a comunidade e no reconhecimento de que os públicos atendidos contribuem de forma efetiva no diálogo sobre os saberes da cidade.

Nesse recorte, o olhar do Projeto de Extensão voltou-se para a cidade, promovendo atividades que buscavam dar visibilidade ao espaço público e convidar a comunidade a vivenciar a urbanidade em tudo que ela pode oferecer, fortalecendo as relações pessoais, fomentando a construção de identidade de bairro e resgatando memórias que contribuem no reconhecimento do espaço da cidade.

A partir desse texto, pretende-se abordar os meios e modos de "fazer extensão" com base nas experiências do projeto em questão. Além disso, busca sistematizar, para fins de registro, relatos do 
que foi realizado no seu primeiro ciclo de atividades realizadas no Bairro Nossa Senhora do Rosário, em Santa Maria - RS.

A comunicação das experiências já vivenciadas objetiva, ainda, vencer a barreira das "situações informais" a que parcelas da extensão universitária se sujeita, como afirmado por a AMORE e LEITÃO (2017), cujas reflexões indicam o fazer de extensão muito conectado na imersão de campo, no diálogo com o contexto e conflitos cotidiano, não preservando tempo e espaço para as construções teóricas necessárias.

\section{O [com]VIDA}

O Projeto de Extensão "Qualidade ambiental urbana: um estudo de identidade urbana para o Bairro Nossa Senhora do Rosário em Santa Maria - RS" nasceu no Curso de Arquitetura e Urbanismo da Universidade Franciscana (UFN) para atender, de forma objetiva, os apelos da Associação de Moradores do Bairro Rosário (AMBRO).

O Bairro do Rosário, como é conhecido e identificado localmente, está localizado na região central da cidade de Santa Maria, com território limitado, principalmente, pelo traçado da antiga ferrovia e a Rua Silva Jardim, rua está onde estão situados três dos quatro conjuntos da Universidade Franciscana.

A fim de aproximar o projeto à comunidade e facilitar a comunicação com esses, o Projeto assumiu o "[com]VIDA" como nome popular, cuja síntese se fazia na ideia de, através das ações extensionistas, trazer vida para as ruas e espaços públicos do Bairro despertando a identidade e sensação de pertencimento a esse.

No seu primeiro ciclo de atividades, o [com]VIDA reuniu dois professores coordenadores, três professores colaboradores, nove acadêmicos voluntários e uma arquiteta voluntária egressa do Curso de Arquitetura e Urbanismo da UFN. Com esse grupo foram promovidas diferentes iniciativas que buscavam a aproximação com a comunidade para reconhecer as potencialidades e fragilidades do Bairro bem como ações de ativação urbana.

Com encontros semanais, o grupo discutia meios de identificar as características do local e de engajar a comunidade nas atividades propostas para a qualificação urbana. Do trabalho de reconhecimento do Bairro, que concentrou grande parte da energia do Projeto no seu primeiro ano, foram executadas algumas ações que contribuíram no fortalecimento do grupo e atenderam ao seu objetivo de atuação junto à comunidade.

Destaca-se que o contato da Associação de Moradores com o Curso de Arquitetura da Universidade Franciscana tornou-se viável, principalmente, pela proximidade física da instituição com o Bairro. A UFN possui quatro conjuntos de edifícios localizados em Santa Maria, dos quais três estão situados na borda do Rosário, como é possível observar na Figura 01. 
Figura 01 - Recorte do mapa de Santa Maria com destaque para o perímetro do Bairro Nossa Senhora do Rosário e localização da UFN.

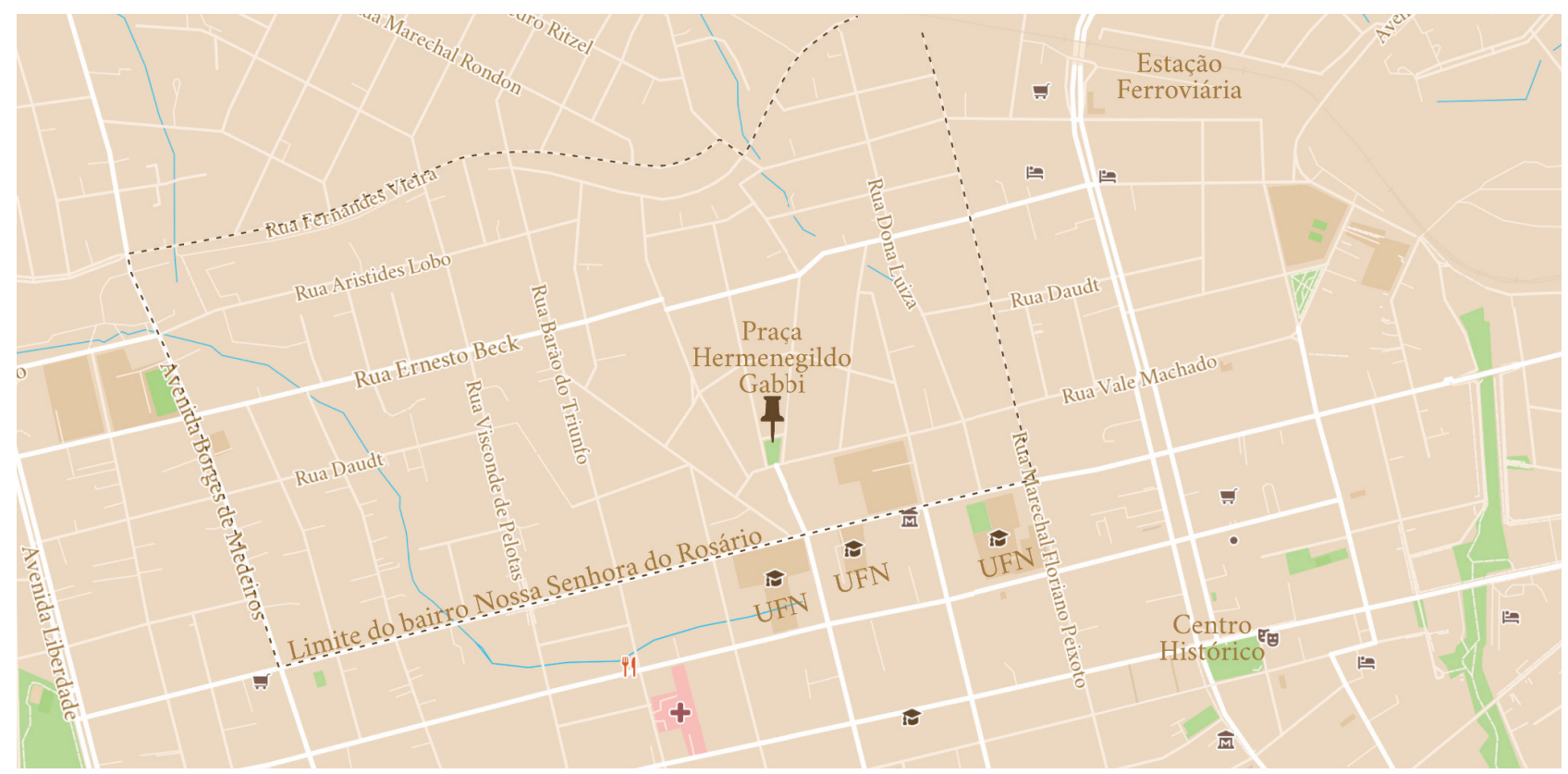

Fonte: Adaptado do Mapbox (2021).

A presença da Universidade é identificada como o principal indutor da mudança de perfil da população residente em parte do Bairro, cujas características têm contribuído de forma efetiva para que a paisagem construída do núcleo histórico do Rosário venha se modificando de forma acelerada nos últimos anos.

O Bairro, que era tradicionalmente reconhecido por tratar-se de "bairro residencial", traz na sua história relações com a ocupação negra no município de Santa Maria, sendo endereço de moradia de trabalhadores que atendiam as demandas do transporte ferroviário e a rotina de regiões mais abastadas da cidade (GRIGIO, 2018).

De bairro predominantemente ocupado por residências unifamiliares, as mudanças de sua ocupação nos últimos anos referem-se ao público universitário, cuja pressão do mercado imobiliário tem construído edificações multifamiliares, principalmente de apartamentos de um e dois dormitórios, que atendem as necessidades daqueles que buscam a região em função da UFN. É dessa mudança de cenário que a AMBRO se mobiliza e busca o Curso de Arquitetura na busca de soluções para o Bairro frente à uma nova realidade de "bairro universitário".

Ao mesmo tempo em que o início dos trabalhos se apoiou em busca por referências bibliográficas que tratassem sobre o histórico do bairro e revelassem as mudanças que o mesmo vem sofrendo, o grupo também se aproximou da comunidade através de encontros com a AMBRO e diversas atividades presenciais pela área, nas quais puderam reconhecer o território, seus atores e sua dinâmica cotidiana.

Para a aproximação com a comunidade o grupo utilizou-se de diferentes métodos de comunicação (Figura 02): conversas espontâneas durante as visitas ao bairro, visitas agendadas, quadros 
interativos em locais específicos (instituições de ensino e eventos), participação nas reuniões da AMBRO, além de convites à comunidade para visita à UFN (roda de conversa e eventos internos). Ainda, o [com]VIDA criou uma página oficial em duas redes sociais que facilitaram a interação, principalmente, com a população universitária do bairro e servem para divulgação e registro das atividades.

Figura 02 - Fotomontagem com atividades realizadas durante a aproximação com a comunidade

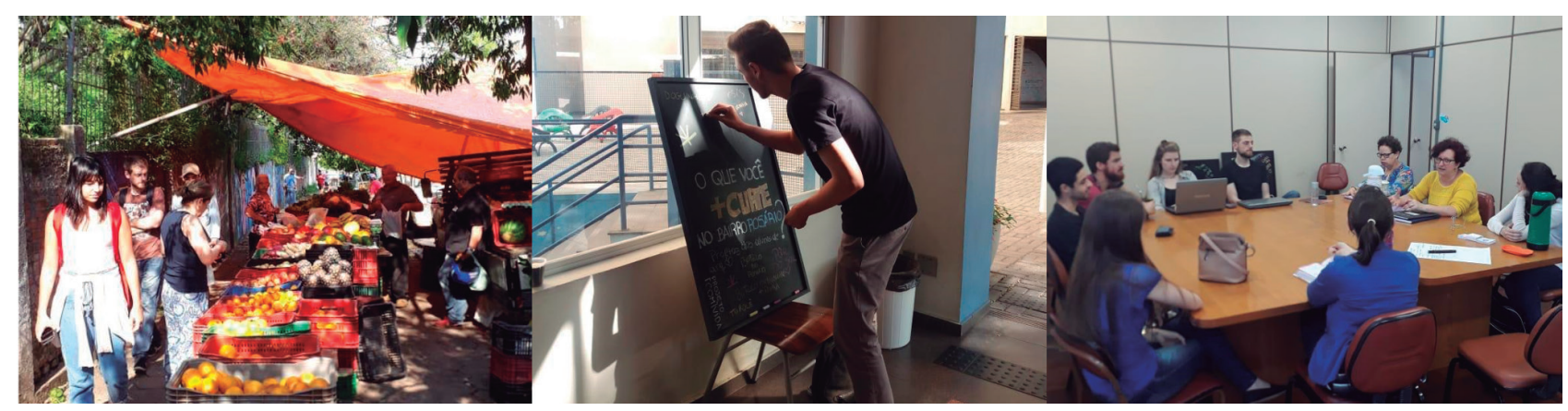

Fonte: Acervo do Projeto [com]VIDA (2021).

As inserções no território aconteceram tanto em passeios programados pelo bairro, inclusive com grupos de alunos externos ao projeto, quanto em visitas para levantamento de dados, diagnóstico e registros fotográficos. O interesse pelo modo de vida e pelas dinâmicas urbanas locais proporcionaram descobertas e vivências que fomentaram diferentes ações pelo grupo a partir do reconhecimento dos equipamentos urbanos e do patrimônio cultural, material e imaterial presentes no bairro que pouco são citados nas bibliografias oficiais.

Entre as demandas descobertas pelo [com]VIDA que poderiam ser atendidas dentro da realidade de um projeto de extensão universitário, a intervenção na praça do bairro foi um marco muito importante para o fortalecimento da relação universidade e comunidade. A ação denominada Domingo [com]VIDA encerrou o primeiro semestre do projeto.

Ainda, as redes sociais permitiram a realização de um concurso fotográfico sobre o bairro que foi intitulado Rosário Novos Olhares. Esta ação mesclou a interação presencial e digital com a comunidade a partir dos registros enviados pelos moradores e visitantes, possibilitando uma nova forma de comunicação e de ampliação do alcance das atividades do projeto de extensão.

No final do primeiro ano de Projeto, foi organizada uma exposição que compilou os registros das ações até então desenvolvidas e apresentou formalmente o [com]VIDA para a comunidade. A exposição que ficou aberta de 12 a 21 de junho de 2019 ocupou a Sala Angelita Stefani, nas dependências do Conjunto III da Universidade Franciscana.

A Figura 03 apresenta o material gráfico produzido pelo grupo para divulgação das ações acima citadas: a ação de urbanismo tático na Praça Hermenegildo Gabbi, o concurso fotográfico e a exposição dos trabalhos realizados no primeiro ano do projeto, nesta ordem. 
Figura 03 - Material gráfico de divulgação das ações realizadas pelo projeto [com]VIDA
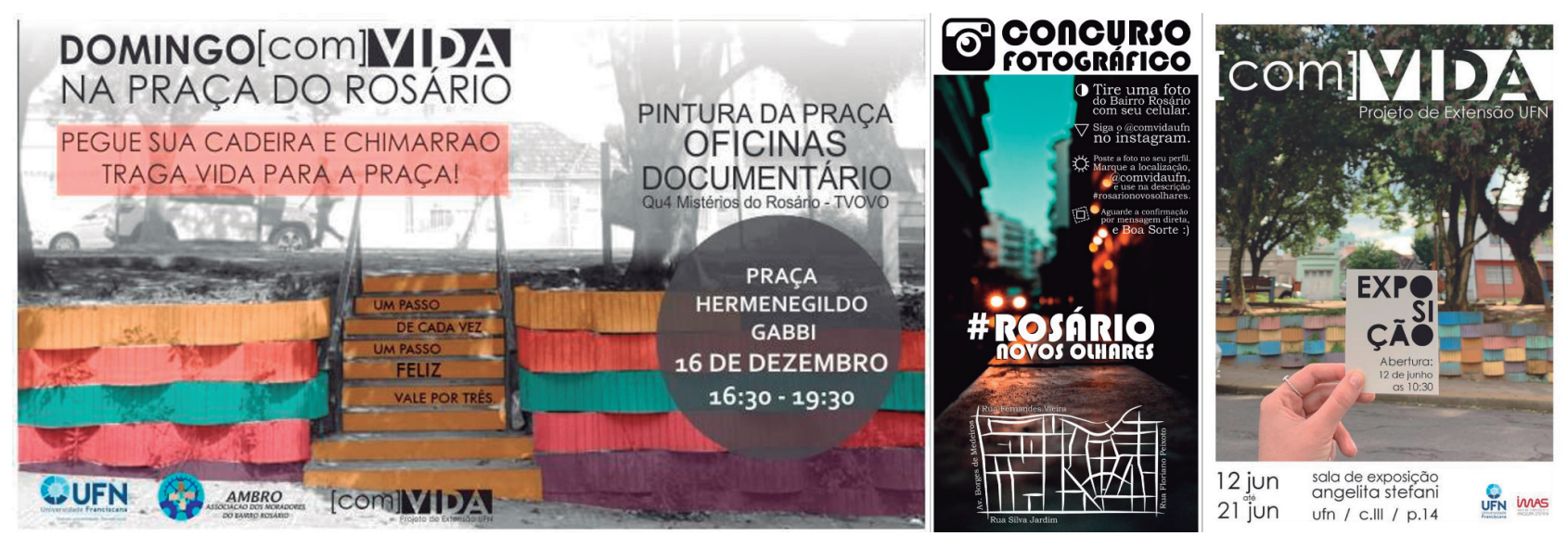

Fonte: Acervo do Projeto [com]VIDA (2021).

A partir dos resultados encontrados com as ações do primeiro ano e motivado pela afirmação de Kevin Lynch (2011) de que "cada cidadão tem vastas associações com alguma parte de sua cidade, e a imagem de cada um está impregnada de lembranças e significados”, foram propostos dois subprojetos vinculados ao [com]VIDA que foram desenvolvidos no segundo ano do projeto. Ambos visavam o fortalecimento da identidade de bairro e reconhecimento das vivências da comunidade através da história oral e de fotografias de família enquanto registro da memória dos moradores. Tais iniciativas são significativas, pois:

Entende-se que o conhecimento da história e memória do lugar pode promover e ampliar um sentimento de respeito às suas características, sua complexidade e suas particularidades, uma vez que essas têm potencial para modificar o espaço urbano, acolhendo as necessárias transformações e fortalecendo a apropriação dos (novos e antigos) moradores com o local. (GUMA, 2019, s/p)

Do trabalho com a história oral foi organizado o Afetos, que pesquisou a história do Bairro Nossa Senhora do Rosário contada por seus moradores. O Retratos Reconstruídos, por sua vez, trabalhou na busca e catalogação de acervos fotográficos particulares, cujas fotografias trouxessem registros da paisagem construída do bairro. Devido à pandemia do COVID-19, os resultados foram compartilhados com a comunidade somente através das redes sociais do [com]VIDA (Figura 04).

Assim, a partir das ações citadas é perceptível o esforço do projeto em ouvir e integrar a comunidade nas atividades, dando sentido à extensão universitária. Ainda, é possível identificar dois objetivos principais do [com]VIDA contemplados nas ações extensionistas: reconhecer o Bairro do Rosário e suas transformações a partir da implantação da UFN, e principalmente, atuar pela qualidade e identidade urbana local. 
Figura 04 - Panfleto de divulgação e identidade do Afetos e do Retratos Reconstruídos
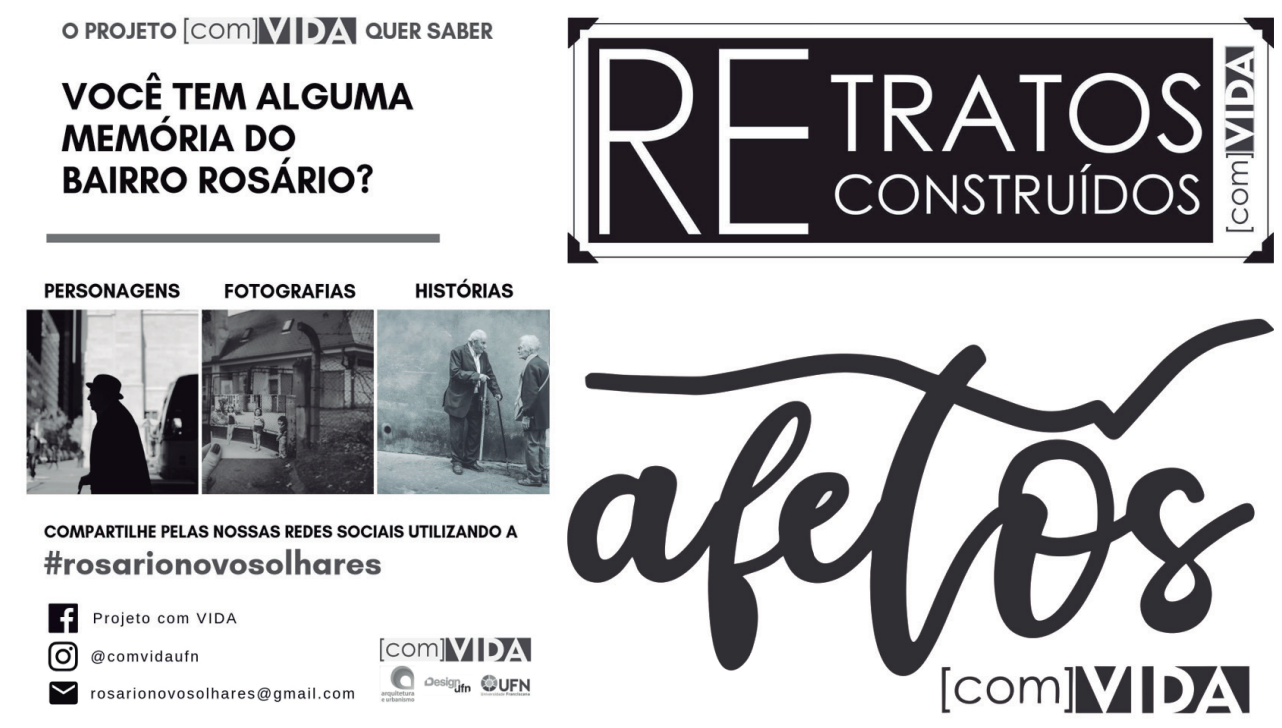

Fonte: Acervo do Projeto [com]VIDA (2021).

\section{PRINCIPAIS AÇÕES DO [com]VIDA NO BAIRRO DO ROSÁRIO}

Uma vez formado o grupo de trabalho do [com]VIDA, os primeiros esforços de atuação foram concentrados em atividades que contribuíssem para que o Projeto reconhecesse a comunidade e o Bairro Nossa Senhora do Rosário. Para tanto, foram realizados levantamentos que envolviam pesquisa bibliográfica e de campo, com incursões pelo bairro a fim de fazer o registro fotográfico da paisagem construída e natural, além de mapear características do espaço urbano.

Paralelamente às atividades de levantamento, iniciaram-se tentativas de aproximação e comunicação com os moradores do Rosário a fim de diversificar os olhares desses a respeito do bairro, uma vez que, até então, o discurso ao qual o [com]VIDA tinha acesso restringia-se aos integrantes da equipe diretiva da AMBRO. A busca por ampliar as percepções acerca da comunidade e território do Rosário fez-se no entendimento de que "a cidade não é construída para uma pessoa, mas para um grande número delas, todas com grande diversidade de formação, temperamento, ocupação e classe social" (LYNCH, 2011, p. 123).

Compreender a multiplicidade de olhares que fazem o Bairro do Rosário se mostrava fundamental para que o [com]VIDA pudesse articular ações pautadas nas características que davam identidade ao território. Enquanto projeto de extensão, o grupo se colocava na posição de observador externo ao bairro, cujo trabalho só alcançaria efetividade se capazes de "penetrar mentalmente" no espaço, como explica Lynch (2011). 
Os bairros são as regiões médias ou grandes de uma cidade, concebidos como dotados de extensão bidimensional. O observador nele "penetra" mentalmente, eles são reconhecíveis por possuírem características comuns que os identificam. Sempre identificáveis a partir do lado interno, são também usados como referência externa quando visíveis de fora ( $\mathrm{LYNCH}$, 2011, p. 52).

Uma estratégia de comunicação adotada com a comunidade foi o uso de quadros interativos distribuídos em alguns edifícios da Universidade Franciscana e na Escola Básica Estadual Cícero Barreto (localizada no Bairro do Rosário). Os quadros levavam perguntas como "O que você mais gosta no bairro do Rosário?" e "O que você menos gosta no bairro do Rosário?”, deixando espaço para que as pessoas respondessem livremente.

Além disso, começaram a ser realizadas reuniões em conjunto com a Associação de Moradores do Bairro do Rosário, buscando entender as necessidades e expectativas a partir das intervenções do projeto de extensão. Após dois meses do início do [com]VIDA, foi promovida uma Roda de Conversa aberta para todos os moradores do bairro, obtendo-se um número satisfatório de participantes com os quais foi possível aproximação para realização de questionário e dinâmicas em relação ao local de moradia desses.

Da etapa de reconhecimento, ficou evidente que existia, mesmo entre os moradores, o desconhecimento do território legal do bairro, sendo que este podia ser entendido formado por dois núcleos: o histórico, próximo à Igreja de Nossa Senhora do Rosário e núcleo inicial de ocupação; e outro, na porção oeste, de urbanização mais recente.

Outro aspecto interessante foi a constatação de pouquíssimos registros históricos oficiais a respeito do Bairro, seja em texto ou fotografia. A história do Bairro do Rosário que, ligada à história da população negra e de trabalhadores braçais de Santa Maria, ainda está muito conectada ao registro oral de moradores e acervos privados. Mostraram-se como fontes importantes da história do Rosário autores como GRIGIO (2018), TOCHETTO (2016) e OLIVEIRA (2017) que abordaram temáticas correlatas ao Bairro em seus estudos acadêmicos.

Buscando responder a premissa de troca universidade-sociedade, elemento característico e definidor de um projeto de extensão, após um período de reconhecimento do espaço de estudo, foram organizadas ações que buscavam, através de atividades práticas, atender aos objetivos de qualificação urbana com enfoque na identidade do bairro Nossa Senhora do Rosário. Dessas ações, três se destacaram: o Domingo [com]VIDA, o Concurso Fotográfico Rosário Novos Olhares e a exposição [com]VIDA Expõe.

\section{Domingo [com]VIDA}

Marcando a finalização do primeiro semestre de atividades do Projeto, em dezembro de 2018 foi organizado o Domingo [com]VIDA. A ação extensionista promoveu uma tarde de intervenções na 
Praça Hermenegildo Gabbi, popularmente conhecida como "Pracinha do Rosário". A praça é o único espaço público de lazer dentro dos limites do bairro. Localizada na borda sul do território, adota um formato triangular resultado da malha viária radial característica de porção do Bairro.

A intervenção, com a perspectiva do urbanismo tático, além da pintura e da limpeza do espaço, proporcionou a socialização da comunidade com os acadêmicos que compunham o Projeto, além de despertar o engajamento e a presença no espaço público. A proposta da ação foi pensada por entender que "se há vida e atividade no espaço urbano, então também existem muitas trocas sociais" (GEHL, 2015, p. 22) que são fundamentais para resgatar a identidade local e fortalecer os laços comunitários.

Além de único espaço público do Bairro, a praça foi escolhida como local da ação por ser indicada como um local importante para o reconhecimento e localização como ponto de referência para a comunidade residente e transeuntes eventuais. Lynch (2011) explica esses lugares como pontos nodais na cidade.

Os pontos nodais são pontos, lugares estratégicos de uma cidade através dos quais o observador pode entrar, são os focos intensivos para os quais ou a partir dos quais ele se locomove. (...) Alguns desses pontos nodais de concentração são o foco e a síntese de um bairro, sobre o qual sua influência se irradia e do qual são símbolo. (LYNCH, 2011, p. 78)

Das especificidades da Praça no que se refere à sua importância para a identidade do bairro, constatou-se a sua condição de abandono por parte do poder público e ocupação por grupos que vinham depredando suas instalações. Do reconhecimento do espaço e análises prévias realizadas pelo grupo do Projeto [com]VIDA e Associação de Moradores, foram organizadas uma série de pequenas atividades que foram executadas em uma tarde, mobilizando cerca de 80 participantes entre comunidade do Bairro Rosário e comunidade acadêmica.

As atividades envolveram a ampliação temporária do espaço da praça com a ocupação de duas vias que a delimitavam para proporcionar a ocupação da rua por pedestres, a limpeza e pintura de muretas que compunham uma espécie de jardim vertical que delimita porção da área verde, uma oficina de desenho com crianças, a criação de uma "vaga viva" e, por fim, para o encerramento do dia, a exibição do documentário “QU4TRO Mistérios do Rosário” com o apoio da TV OVO (Fig. 05).

Figura 05 - Fotomontagem com atividades da intervenção do Domingo [com]VIDA

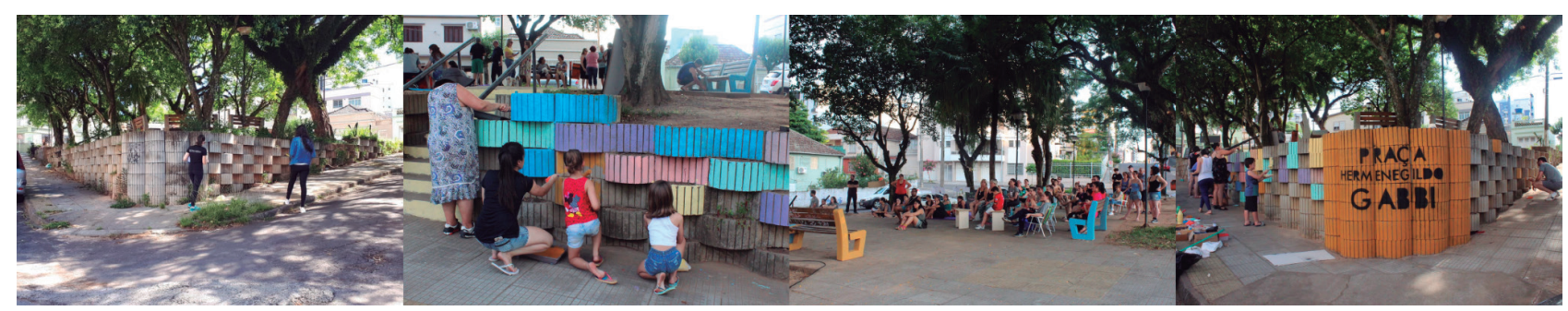

Fonte: Acervo do Projeto [com]VIDA (2021) 


\title{
Rosário Novos Olhares
}

A partir da leitura que o Projeto [com]VIDA vinha fazendo a respeito da comunidade e do Bairro, a proposta do Concurso Fotográfico surgiu com as intenções de provocar novos olhares para o território, atingindo mais pessoas e buscando entender como a população reconhecia o Rosário (DÉCIMO et al, 2019). O meio de participação adotava as fotografias usando o celular, e podiam ser compartilhadas com o Projeto via e-mail ou redes sociais do [com]VIDA, de forma que simplificasse o processo a fim de atingir e envolver mais público.

O uso da fotografia para cativar os olhares para o Bairro do Rosário, além de uma ferramenta democrática para a participação coletiva, tendo em vista o acesso de celulares pela população, é também uma estratégia de estudo acerca do território, como confirma Gehl (2013).

\begin{abstract}
Enquanto o olho humano pode observar e registrar, os filmes e as fotografias são bons auxiliares no campo da comunicação. Fotografar e filmar também podem ser boas ferramentas para congelar situações para documentação e análise posterior. Quando se estuda fotografias e filmes, é possível descobrir novas conexões ou detalhar situações urbanas complexas, difíceis de entender a olho nu. (GEHL, 2013, p. 31)
\end{abstract}

O concurso ficou aberto cerca de dois meses e teve a participação de 89 fotografias que foram posteriormente apresentadas em formato digital na [com]VIDA Expõe. As dez melhores fotografias, eleitas por um júri externo ao Projeto, foram impressas, sendo que quatro foram premiadas com brindes ofertados por empresas localizadas no Bairro.

Segundo Décimo (2019), mesmo que a intenção do concurso fosse provocar um olhar mais amplo acerca do território, das fotografias recebidas 48 puderam ser localizadas e ratificam a Igreja do Rosário, e seus arredores como espaços que identificam o Bairro, concentrando o maior número de registros, como apontado na Figura 06.

Figura 06 - Mapeamento de fotografias recebidas no Concurso Novos Olhares e imagens premiadas

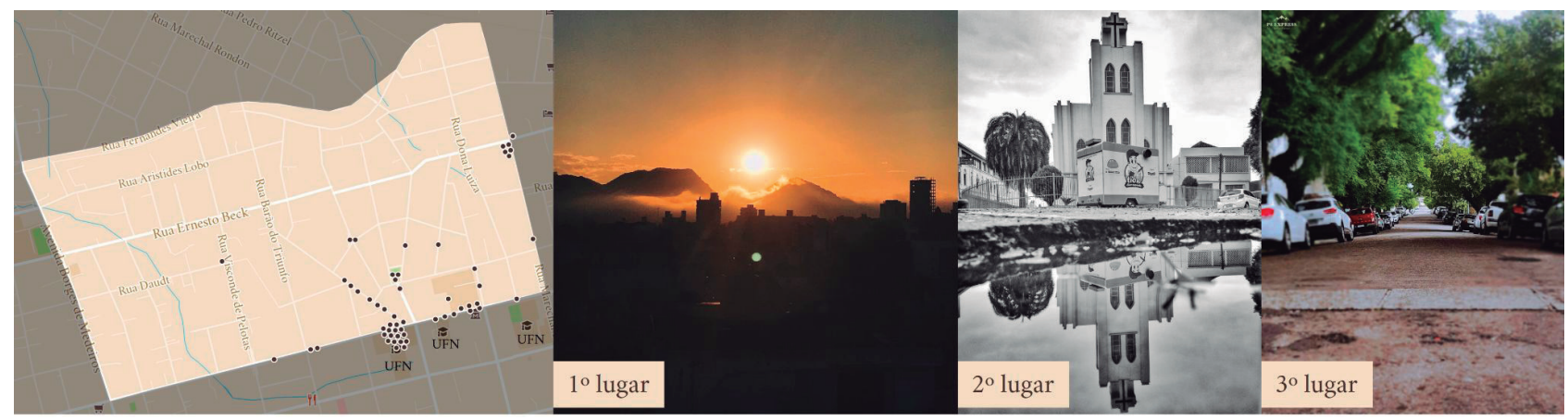

Fonte: Acervo do Projeto [com]VIDA (2021)

Dos resultados obtidos nesta ação é possível reafirmar a hipótese levantada pelo [com]VIDA de que a identificação dos moradores e frequentadores da região com o Bairro do Rosário se faz a 
partir dos pontos nodais. Tal constatação encontra aporte teórico novamente na publicação A Imagem da Cidade de Kevin Lynch, que afirma:

Não é incomum o tipo de bairro com um núcleo forte e cercado por um gradiente temático que vai desaparecendo aos poucos. Às vezes, de fato, um ponto nodal forte pode criar uma espécie de bairro numa zona homogênea mais ampla, simplesmente por "radiação", ou seja, pela sensação de proximidade com o ponto nodal. (LYNCH, 2011, p. 78)

\section{[com]VIDA expõe}

Ao final do primeiro ano do Projeto promoveu-se a "[com]VIDA expõe" com o objetivo de compartilhar os estudos e ações já realizadas. A exposição, que ocupou a Sala de Exposições Angelita Stefani, localizada no Conjunto III da Universidade Franciscana, ficou aberta à visitação durante duas semanas em junho de 2019. Na cerimônia de abertura, que compôs parte das atividades do $11^{\circ}$ Fórum de Arquitetura e Urbanismo, foram divulgados os vencedores do Concurso Fotográfico Rosário Novos Olhares.

A exposição foi organizada propondo um percurso que resgatava parte do trabalho já desenvolvido, associando as premissas e bases teóricas do Projeto [com]VIDA com a divulgação de resultados já alcançados. A atividade se somou ao Projeto ao aproximá-lo de seus objetivos iniciais de reforçar a identidade local, promovendo a sensação de comunidade por parte de moradores do Bairro do Rosário.

Em um primeiro momento, a exposição apresentava os estudos realizados durante as etapas iniciais de levantamento, trazendo uma perspectiva técnica do Bairro a partir de mapeamentos, conteúdo histórico e material textual. Em outro espaço, são compartilhados fisicamente produtos desenvolvidos pelo projeto e pelo curso de Arquitetura e Urbanismo, como a remontagem da "vaga viva" utilizada no Domingo [com]VIDA e maquetes físicas elaboradas por acadêmicos.

Por fim, finalizando o percurso, outro ambiente trazia em modo digital as fotografias participantes do Rosário Novos Olhares e as dez imagens impressas selecionadas pelos jurados do Concurso, com destaque para as premiadas (Fig. 07).

Figura 07 - Fotomontagem dos ambientes da "[com]VIDA expõe"

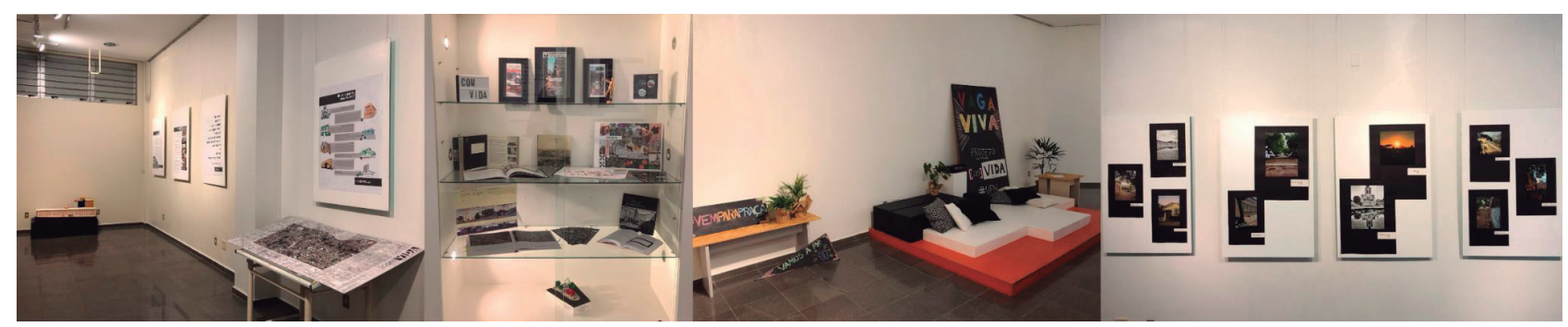

Fonte: Acervo do Projeto [com]VIDA (2021) 
Durante a exposição foi possível levar parte da comunidade do Bairro para dentro da Universidade, além de apresentar o local para diversas pessoas que circulavam pelo território apenas em função da presença da UFN. Nos relatos de moradores que visitaram a exposição, é sensível que estes puderam ver seu bairro através de outra perspectiva, sentindo-se valorizados e homenageados pelo Projeto.

\section{CONSIDERAÇÕES FINAIS}

O [com]VIDA nasceu a partir da aproximação da Associação de Moradores do Bairro do Rosário à Universidade Franciscana, buscando apoio da instituição na solução de alguns problemas pontuais do bairro. Desse contato, o Curso de Arquitetura e Urbanismo identificou a potencialidade de trabalho como Projeto de Extensão.

Ao atuar como extensão, o [com]VIDA entende a relação entre universidade e sociedade como uma oportunidade de desenvolvimento mútuo, democratizando o acesso de saberes construídos no âmbito acadêmico com os saberes daqueles que vivem e fazem a cidade no cotidiano. Nesse aspecto, o Projeto responde à "concepção de que a universidade carrega, por uma lado, um caráter social, uma vertente relacionada à socialização do conhecimento" (INCROCCI; ANDRADE, 2018, p. 189).

O trabalho realizado pelo Projeto junto do Bairro do Rosário durou cerca de dois anos, desenvolvendo atividades de caráter teórico e prático que fomentaram, de forma efetiva, a troca entre a instituição de ensino e comunidade, logo, fez extensão.

Dos resultados expostos nesse texto, explicitaram-se aqueles julgados de maior impacto. Ainda assim, destaca-se que uma série de outras pequenas ações foram realizadas na rotina de trabalho do grupo extensionista, de modo que os ganhos na formação humana dos acadêmicos participantes não são aqui dimensionados.

A atuação do [com]VIDA sempre esteve pautada no reconhecimento do direito à cidade, na valorização do espaço público, e na sociabilidade pautados no urbanismo social e colaborativo. Autores como Lynch (1997), Lefebvre (2009), Gehl (2013) entre outros trazem as bases teóricas para o fazer prático do Projeto.

Inspirados em Lynch (2011, p. 1) que diz que "a cada instante, há mais do que o olho pode ver, mais do que o ouvido pode perceber, um cenário, uma paisagem esperando para serem explorados", o [com]VIDA ampliou suas possibilidade de trabalho no último ano para outros territórios, desenvolvendo ações para além do Bairro Nossa Senhora do Rosário.

Reforça-se, nesse sentido, o entendimento da extensão universitária como um processo não-linear, visto achar-se constantemente em um sistema que se retroalimenta na construção da identificação e reconhecimento de objetos de estudo. Além disso, faz-se na participação de comunidades externas à universidade, cujo tempo de trabalho muitas vezes difere do tempo do fazer acadêmico, de forma que o reconhecimento dos saberes populares constantemente realinha ações. 


\section{REFERÊNCIAS}

AMORE, Caio. LEITÃO, Karina. Extensão em Prelúdio: crônica das oficinas de práticas urbanas do XVII ENANPUR. In: D’OTTAVIANO, Camila; ROVATI, João. (orgs.). Para Além da Sala de Aula: extensão universitária e planejamento urbano e regional. São Paulo: Faculdade de Arquitetura e Urbanismo da Universidade de São Paulo e Associação Nacional de Pós-graduação e Pesquisa em Planejamento Urbano e Regional, 2017.

DÉCIMO, Luíse. ALCÂNTARA, Marina de. PAVÃO, Nicole. GUMA, Juliana. A Percepção do Bairro Nossa Senhora Do Rosário pelo Concurso Fotográfico Rosário Novos Olhares. In: SIMPÓSIO DE ENSINO, PESQUISA E EXTENSÃO, 23. Anais... Santa Maria, RS: Universidade Franciscana, 2019.

FOREXT. Fórum Nacional de Extensão e Ação Comunitária das Instituições Comunitárias de Ensino Superior. Carta de Porto Alegre: Desafios da Extensão frente ao cenário educacional brasileiro. Porto Alegre, 07 nov. 2017. Disponível em: https://bit.ly/2Z52ncV. Acesso em: 24 maio 2021.

GEHL, Jan. Cidade para pessoas. 2. ed. São Paulo: Perspectiva, 2013.

GRIOGIO, Ênio. "No alvoroço da festa, não havia corrente de ferro que os prendesse, nem chibata que intimidasse": A comunidade negra de Santa Maria e sua Irmandade do Rosário (18731942). Santa Maria: Câmara Municipal de Vereadores de Santa Maria, 2018.

INCROCCI, L. M. de M. C.; DE ANDRADE, T. H. N. O fortalecimento da extensão no campo científico: uma análise dos editais ProExt/MEC. Sociedade e Estado, [S. l.], v. 33, n. 01, p. 189-214, 2018. Disponível em: https://bit.ly/3phtvAx. Acesso em: 21 maio. 2021.

LEFEBVRE, Henri. O direito à cidade. São Paulo: Centauro Editora, 2009.

LYNCH, Kevin. A imagem da cidade. Traduzido por Jefferson Luiz Camargo. São Paulo: Martins Fontes, 1997.

OLIVEIRA, Franciele Rocha de. Dos laços entre José e Innocência: trajetórias de uma família negra entre a escravidão e a liberdade no Rio Grande do Sul. Dissertação (mestrado). Universidade Federal de Santa Maria, Centro de Ciências Sociais e Humanas, Programa de Pós-graduação em História, RS, 2017.

TOCHETTO, Daniel. Santa Maria: uma história precursora do planejamento urbano no Rio Grande do Sul. Porto Alegre : Corag/CAU-RS, 2016. 